\title{
External quality assessment of malaria microscopy diagnosis in selected health facilities in Western Oromia, Ethiopia
}

\author{
Getachew Sori $^{1}$, Olifan Zewdie ${ }^{2 *}$, Geletta Tadele ${ }^{2}$ and Abdi Samuel ${ }^{2}$
}

\begin{abstract}
Background: Accurate early diagnosis and prompt treatment are one of the key strategies to control and prevent malaria disease. External quality assessment is the most effective method for evaluation of the quality of malaria microscopy diagnosis. The aim of this study was to assess the quality of malaria microscopy diagnosis and its associated factors in selected public health facility laboratories in East Wollega Zone, Western Ethiopia.

Methods: Facility-based cross-sectional study design was conducted in 30 randomly selected public health facility laboratories from November 2014 to January 2015 in East Wollega Zone, Western Ethiopia. Ten validated stained malaria panel slides with known Plasmodium species, developmental stage and parasite density were distributed. Data were captured; cleaned and analyzed using SPSS version 20 statistical software-multivariate logistic regressions and the agreement in reading between the peripheral diagnostic centers and the reference laboratory were done using kappa statistics.

Results: A total of 30 health facility laboratories were involved in the study and the overall quality of malaria microscopy diagnosis was poor (62.3\%). The associated predictors of quality in this diagnosis were in-service training $[(A O R=16,95 \% \mathrm{Cl}(1.3,1.96)]$, smearing quality $[(A O R=24,95 \% \mathrm{Cl}(1.8,3.13)]$, staining quality $[(A O R=15,95 \% \mathrm{Cl}(2.35$, 8.61), parasite detection $[(A O R=9,95 \% \mathrm{Cl}(1.1,8.52)]$ and identification skills $[(A O R=8.6,95 \% \mathrm{Cl}(1.21,1.63)]$. Eighteen (60\%) of health facility laboratories had in-service trained laboratory professionals on malaria microscopy diagnosis.
\end{abstract}

Conclusion: Overall quality of malaria microscopy diagnosis was poor and a significant gap in this service was observed that could impact on its diagnostic services.

Keywords: External quality assessment, Malaria microscopy, Western Oromia

\section{Background}

Malaria remains a major global public health challenge. In 2016, 91 countries reported a total of 216 million cases of malaria, an increase of 5 million cases over the previous year. The global tally of malaria deaths reached 445,000 deaths, about the same number reported in 2015. The WHO African Region continues to account for about $90 \%$ of malaria cases and deaths worldwide. Fifteen countries-all but one in sub-Saharan Africa-carry $80 \%$

\footnotetext{
*Correspondence: olifangdr@gmail.com

2 Department of Medical Laboratory Sciences, College of Medical and Health Sciences, Wollega University, P.O. Box: 395, Nekemte, Ethiopia Full list of author information is available at the end of the article
}

of the global malaria burden [1]. The malaria parasite is transmitted from an infected person to another by the bite of a female Anopheles mosquito. Transmission can occur only after the parasite has been inside the mosquito for at least a week [2].

Rapid and effective malaria diagnosis not only alleviates the suffering but also decreases community transmission. The nonspecific nature of clinical signs and symptoms of malaria may result in over-treatment of malaria or non-treatment of other diseases in malariaendemic areas, and misdiagnosis in non-endemic areas [3]. In the laboratory, malaria is diagnosed using different techniques such as conventional microscopic diagnosis by staining thin and thick peripheral blood smears, 
and other concentration techniques, such as quantitative buffy coat (QBC) method, rapid diagnostic tests (RDTs) and molecular diagnostic methods [2].

The World Health Organization (WHO) recommends cross-checking of blood slides. A sample of routine blood slides is sent to the reference laboratory, where it is checked for accuracy. External quality assessment (EQA) programmes is an alternative approach. In such programmes, the reference laboratory sends stained blood film samples to the peripheral laboratories, which assess them and submit a report, after which they are given feedback about the correct results and their own performance [4].

The high sensitivity of diagnosis in malaria-endemic areas is particularly important for the most vulnerable population groups, such as young children and nonimmune populations, in whom the disease can rapidly be fatal [5]. Malaria control requires a functional laboratory set-up with quality diagnostic service, trained professionals and microscopists to halt the burden. This work requires concentration in order to assess the quality of blood film malaria microscopy for the detection of Plasmodium species by proficient testing, blinded slide rechecking using checklist to identify any gaps in providing malaria services in selected health facility laboratories in the Western Oromia, Ethiopia.

\section{Methods}

\section{Study area and period}

This study was conducted in East Wollega Zone of the Oromia National Regional State, Western Oromia, Ethiopia, from November 2014 to January 2015. The temperature was $10.9-33.9^{\circ} \mathrm{C}$, annual rainfall was 1000 $2400 \mathrm{~mm}$ and topography was $4.91 \%$ high land, $53.17 \%$ mid land, and $41.92 \%$ low land. The zone has 61 public health facilities, one of which is a referral hospital, one a district hospital, and 59 health centres [6]. All health facility laboratories provide malaria microscopy services, except Gaba Jimata health centre in Gida Ayana Woreda. The study was conducted in 30 health facility laboratories that were randomly selected from 60 malaria microscopy providing public health facilities.

\section{Study procedures}

Verified stained panel slides were distributed to 30 laboratory professionals from selected public health facilities and the results were collected. The validated panel slides were distributed for reading to all selected malaria microscopy health facility laboratory professionals. The panel slides included 10 stained samples with different composition of Plasmodium species, the developmental stage of the parasite and parasite density as recommended by national guidelines [7]. The time allowed for reading 10 slides was $50-70 \mathrm{~min}$ according to national guidelines recommend examination of 100/HPF (High Power Field) $(100 \times$ objective $)$. EQA of malaria microscopy is an essential requirement for malaria care in a district. The focus of EQA is on the identification of laboratories where there may be serious problems resulting in poor performance, not on identification of individual slide errors or validation of individual patient diagnosis. It helps to ensure the trust-worthiness of smear results through the following:

\section{On-site evaluation}

Malaria laboratory activities in all selected malaria microscopy diagnosis in the health facilities were observed and all heads of departments of the respective health facilities were interviewed using WHO-AFRO checklists to obtain a realistic assessment of the overall operational conditions and skills in the laboratory.

\section{Blind rechecking}

Slides are rechecked for quality of blood film preparation, staining and accuracy of result. Rechecking reflects the true performance of routine diagnostic services at health facility level. For this study, the blood film slides were collected from the selected malaria microscopy providing health facilities, which were selected in accordance with WHO recommendation of a minimum of five positives and five negatives slides per month.

\section{Data analysis}

Data were captured, cleaned and analysed using SPSS version 20 statistical software-multivariate logistic regressions and $P$ value of less than 0.05 was considered to be statistically significant. The specificities, sensitivities, positive predictive value, negative predictive value of slide reading by the laboratory professionals were assessed. Agreement in reading between peripheral diagnostic centres and the reference laboratory readings were interpreted using kappa value. Accuracy is defined as the closeness of the measured result to the true value and malaria microscopy was used as the gold standard in the study.

\section{Results}

\section{Quality of malaria microscopy: panel slides}

A total of 300 panel slides were distributed to 30 malaria microscopy diagnosing centres for 30 laboratory personnel. Of the total facilities, 6 (20\%) of laboratory professionals scored an excellent agreement with reference reader $(\mathrm{kappa}=1.00)$ on parasite detection and $6(20 \%)$ scored slight agreement $($ kappa $=0.0-0.2)($ Table 1$)$.

Based on national guideline for evaluation of laboratory professionals on panel slide examination, 1 (3.3\%) of 
Table 1 Sensitivity, specificity and agreement of each health facility laboratory professionals with level 1 malaria microscopist on malaria microscopy diagnosis Western Oromia, Ethiopia

\begin{tabular}{|c|c|c|c|c|c|c|}
\hline Id of HF lab. & Sensitivity \% & Specificity \% & NPV & PPV & Agreement (\%) & Kappa value \\
\hline Lab 1 & 88 & 50 & 50 & 88 & 80 & 0.4 \\
\hline Lab 2 & 71 & 50 & 20 & 100 & 70 & 0.4 \\
\hline Lab 3 & 88 & 50 & 20 & 88 & 80 & 0.6 \\
\hline Lab 4 & 75 & 100 & 50 & 100 & 80 & 0.5 \\
\hline Lab 5 & 83 & 50 & 25 & 100 & 80 & 0.7 \\
\hline Lab 6 & 88 & 100 & 67 & 100 & 90 & 0.7 \\
\hline Lab 7 & 88 & 100 & 67 & 100 & 90 & 0.7 \\
\hline Lab 8 & 100 & 100 & 100 & 100 & 100 & 1.0 \\
\hline Lab 9 & 63 & 100 & 40 & 100 & 70 & 0.4 \\
\hline Lab 10 & 63 & 50 & 25 & 83 & 60 & 0.1 \\
\hline Lab 11 & 88 & 100 & 67 & 100 & 90 & 0.7 \\
\hline Lab 12 & 71 & 100 & 50 & 83 & 80 & 0.6 \\
\hline Lab 13 & 100 & 100 & 100 & 100 & 100 & 1.0 \\
\hline Lab 14 & 75 & 100 & 50 & 100 & 80 & 0.5 \\
\hline Lab 15 & 100 & 100 & 100 & 100 & 100 & 1.0 \\
\hline Lab 16 & 63 & 50 & 25 & 83 & 60 & 0.1 \\
\hline Lab 17 & 88 & 100 & 67 & 100 & 90 & 0.7 \\
\hline Lab 18 & 75 & 100 & 50 & 100 & 80 & 0.5 \\
\hline Lab 19 & 63 & 50 & 25 & 83 & 60 & 0.1 \\
\hline Lab 20 & 88 & 100 & 67 & 100 & 90 & 0.7 \\
\hline Lab 21 & 100 & 100 & 100 & 100 & 100 & 1.0 \\
\hline Lab 22 & 63 & 100 & 40 & 100 & 70 & 0.4 \\
\hline Lab 23 & 33 & 50 & 20 & 80 & 40 & 0.3 \\
\hline Lab 24 & 63 & 100 & 40 & 100 & 70 & 0.4 \\
\hline Lab 25 & 63 & 50 & 25 & 83 & 60 & 0.1 \\
\hline Lab 26 & 75 & 100 & 50 & 100 & 80 & 0.5 \\
\hline Lab 27 & 88 & 100 & 67 & 100 & 90 & 0.7 \\
\hline Lab 28 & 50 & 50 & 20 & 80 & 50 & 0.0 \\
\hline Lab 29 & 100 & 100 & 100 & 100 & 100 & 1.0 \\
\hline \multirow[t]{2}{*}{ Lab 30} & 100 & 100 & 100 & 100 & 100 & 1.0 \\
\hline & $77 \%$ & $83.3 \%$ & & & $78 \%$ & 0.5 \\
\hline
\end{tabular}

laboratory professionals correctly read all positive slides with correct parasite quantification. Twelve (40\%) did not try to report parasite density. 17 (56.7\%) correctly quantified the parasite density in at least one positive slide which agreed with the reference density established for each slide. Six (20\%) of laboratory professionals reported all positive slides as positive and $20(66.7 \%)$ correctly reported all negative slides. Twenty-nine (96.7\%) of participants missed species identification in at least one positive slide (Table 2).

Of 300 panel slides, 240 positive panel slides were distributed which comprised 90 (37.5\%) Plasmodium falciparum, 90 (37.5\%) Plasmodium vivax and 60 (25\%) mixed of P. falciparum and P. vivax. Forty-two (46.7\%) and $47(52.2 \%)$ of the slides were correctly detected and identified for $P$. falciparum and $P$. vivax, respectively. Detection error was reported in 33 (36.7\%) for P. falciparum, 22 (24.5\%) for P. vivax and 70\% Plasmodium species identification error from mixed infection. Health facilities that participated in the EQA programme had considerable agreement $(k a p p a=0.75)$ with reference reader on malaria detection by microscopy when compared with health facilities that did not participate in the EQA programme (kappa value $=0.31$. Comparison between in-service training in malaria detection was higher in trained laboratory professionals (kappa $=0.58$ ) when it was compared with untrained in-service professionals in selected health the facilities $(k a p p a=0.56)($ Table 3$)$. 
Table 2 Grading of laboratory performance based on result of panel slides in selected public health facility laboratories Western Oromia, Ethiopia

\begin{tabular}{|c|c|c|c|c|c|c|c|c|}
\hline HF Lab. ID & $\begin{array}{l}\text { Positive } \\
\text { reported } \\
\text { as negative } \\
\text { or vice versa } \\
\text { (zero points/ } \\
\text { slide) }\end{array}$ & $\begin{array}{l}\text { Positive } \\
\text { reported } \\
\text { as positive } \\
\text { (three points/ } \\
\text { slide) }\end{array}$ & $\begin{array}{l}\text { Correct } \\
\text { species (three } \\
\text { points/slide) }\end{array}$ & $\begin{array}{l}\text { Correct } \\
\text { parasite stage } \\
\text { (two points/ } \\
\text { slide) }\end{array}$ & $\begin{array}{l}\text { Correct } \\
\text { parasite load } \\
\text { (two points/ } \\
\text { slide) }\end{array}$ & $\begin{array}{l}\text { Negative } \\
\text { reported } \\
\text { as negative ten } \\
\text { points per slide }\end{array}$ & $\begin{array}{l}\text { Cumulative } \\
\text { score }\end{array}$ & Performance \\
\hline Lab-1 & $2^{*} 0=0$ & 21 & 12 & 8 & 8 & 10 & 59 & Poor \\
\hline Lab-2 & $3^{*} 0=0$ & 15 & 6 & 4 & 6 & 20 & 51 & Poor \\
\hline Lab-3 & $5 \times 0=0$ & 12 & 0 & 0 & 0 & 10 & 22 & Poor \\
\hline Lab-4 & $2 * 0=0$ & 18 & 9 & 6 & 4 & 20 & 57 & Poor \\
\hline Lab-5 & $4 \times 0=0$ & 15 & 6 & 4 & 0 & 10 & 35 & Poor \\
\hline Lab-6 & $1 \times 0=0$ & 21 & 18 & 12 & 4 & 10 & 65 & Poor \\
\hline Lab-7 & $1 \times 0=0$ & 21 & 8 & 8 & 4 & 20 & 61 & Poor \\
\hline Lab-8 & No error & 24 & 24 & 16 & 16 & 20 & 100 & Excellent \\
\hline Lab-9 & $3 \times 0=0$ & 15 & 0 & 0 & 0 & 20 & 35 & Poor \\
\hline Lab-10 & $4 \times 0=0$ & 15 & 0 & 0 & 0 & 10 & 25 & Poor \\
\hline Lab-11 & $1 \times 0=0$ & 21 & 21 & 14 & 6 & 20 & 82 & Good \\
\hline Lab-12 & $2 \times 0=0$ & 18 & 12 & 8 & 6 & 20 & 64 & Poor \\
\hline Lab-13 & No error & 24 & 18 & 12 & 6 & 20 & 80 & Good \\
\hline Lab-14 & $2 \times 0=0$ & 18 & 3 & 2 & 0 & 20 & 43 & Poor \\
\hline Lab-15 & No error & 24 & 21 & 14 & 6 & 20 & 85 & Good \\
\hline Lab-16 & $4 \times 0=0$ & 15 & 3 & 2 & 0 & 10 & 30 & Poor \\
\hline Lab-17 & $1 \times 0=0$ & 21 & 18 & 12 & 8 & 20 & 79 & Good \\
\hline Lab-18 & $2 \times 0=0$ & 18 & 9 & 6 & 4 & 20 & 57 & Poor \\
\hline Lab-19 & $4 \times 0=0$ & 15 & 6 & 4 & 0 & 10 & 35 & Poor \\
\hline Lab-20 & $1 \times 0=0$ & 21 & 18 & 12 & 6 & 20 & 77 & Good \\
\hline Lab-21 & No error & 24 & 21 & 14 & 4 & 20 & 83 & Good \\
\hline Lab-22 & $3 \times 0=0$ & 15 & 3 & 2 & 0 & 20 & 40 & Poor \\
\hline Lab-23 & $5 \times 0=0$ & 12 & 6 & 4 & 0 & 10 & 32 & Poor \\
\hline Lab-24 & $3 \times 0=0$ & 15 & 3 & 2 & 0 & 20 & 40 & Poor \\
\hline Lab-25 & $4 \times 0=0$ & 15 & 9 & 6 & 2 & 10 & 42 & Poor \\
\hline Lab-26 & $2 \times 0=0$ & 18 & 9 & 6 & 0 & 20 & 53 & poor \\
\hline Lab-27 & $1 \times 0=0$ & 21 & 15 & 10 & 6 & 20 & 72 & Poor \\
\hline Lab-28 & $5 \times 0=0$ & 12 & 0 & 0 & 0 & 10 & 22 & Poor \\
\hline Lab-29 & No error & 24 & 21 & 14 & 8 & 20 & 87 & Good \\
\hline Lab-30 & No error & 24 & 21 & 14 & 8 & 20 & 87 & Good \\
\hline \multicolumn{7}{|c|}{ Overall average points } & 57 & Poor \\
\hline
\end{tabular}

\section{Random blind rechecking}

Overall sensitivity and specificity of health facilities in detection and identification of Plasmodium species were 78 and $83.7 \%$, respectively. The overall false positive and false negative rates were $98(24.4 \%)$ and $85(14.4 \%)$, respectively and the overall agreement between health facility laboratory and regional laboratory experts on malaria microscopy diagnosis (random blind rechecking) was $82 \%$ (kappa $=0.62)$.
Professional background and number of laboratory professionals in selected laboratories

The selected health facility laboratories had a total of 53 laboratory professionals, of which 17 (32\%) were degree and 36 (68\%) were diploma level educated. 17 (56.7\%) of health facilities had 2 laboratory professionals and 12 (40\%) 1 laboratory professional. Of the laboratory professionals, $39(73.6 \%)$ were trained in malaria 
Table 3 Overall sensitivity, specificity and agreement of public health facility laboratory professionals with level 1 malaria microscopist in detecting malaria parasites Western Oromia, Ethiopia

\begin{tabular}{|c|c|c|c|c|}
\hline Peripheral laboratory & Sensitivity & Specificity & Agreement \% & Kappa value \\
\hline & $77 \%$ & $83.3 \%$ & 78 & 0.50 \\
\hline \multicolumn{5}{|l|}{ In-service training } \\
\hline Trained & 81.2 & 90.9 & 83.2 & 0.578 \\
\hline Untrained & 64.0 & 68.7 & 65 & 0.56 \\
\hline \multicolumn{5}{|l|}{ EQA participation } \\
\hline Participated & 89.4 & 96.1 & 90.7 & 0.746 \\
\hline Not participated & 66.9 & 76.4 & 68.8 & 0.3077 \\
\hline \multicolumn{5}{|l|}{ Qualification } \\
\hline B.Sc. degree & 82.5 & 90 & 84 & 0.592 \\
\hline Diploma & 73.8 & 82.5 & 75.5 & 0.42 \\
\hline
\end{tabular}

microscopy diagnosis. Fifty $(94.3 \%)$ of the laboratory personnel had service of 2 and more years.

\section{Factors associated with the quality of malaria microscopy}

To refine any confounding factors, a multivariate logistic regression model was used. According to this model, factors such as in-service training, quality of staining and quality of smearing, remained the predictors for quality of malaria microscopy. Trained laboratory professionals on malaria microscopy diagnosis and quality assurance were 16 times more likely to produce quality of malaria microscopy diagnosis than untrained laboratory professionals $[(\mathrm{AOR}=16,95 \% \mathrm{CI}$ of $(1.3-1.96)]$. Health facility laboratories preparing good stained blood films were 10 times more likely to harvest good quality in the malaria microscopy diagnosis than poorly staining blood films $[(\mathrm{AOR}=15,95 \% \mathrm{CI}$ of $(2.35,8.61)]$. Preparing good blood films was 24 times more likely in quality of malaria microscopy than poorly performing blood films [(AOR $=$ $24,95 \%$ CI of $(1.8,3.13)]$ (Table 4$)$.

\section{Discussion}

The overall quality of malaria microscopy in the assessed public health facility laboratories was $62.3 \%$, which was considered to be poor. An ISO 15189 document requirement for quality and competence recommends above or equal to $80 \%$ [8]. This difference may be due to lack of training in malaria diagnosis and quality assurance, but was similar to the study conducted in Pakistan in which quality of malaria microscopy diagnosis was poor [9].

The current study revealed, 18 (60\%) of health facility laboratories had in service trained laboratory professionals on malaria microscopy and a better quality of malaria microscopy diagnosis than those with no trained laboratory professionals $[(\mathrm{AOR}=16(1.3-1.96)]$. A similar study conducted in health facilities in Oromia Regional State indicated $24 \%$ of health facilities participated laboratories
Table 4 Factors associated with quality of malaria microscopy in selected public health facility laboratories Western Oromia, Ethiopia

\begin{tabular}{|c|c|c|c|c|c|}
\hline \multirow[t]{2}{*}{ Variables } & \multicolumn{2}{|c|}{$\begin{array}{l}\text { Malaria microscopy } \\
\text { quality }\end{array}$} & \multicolumn{3}{|l|}{ OR (95\%) Cl } \\
\hline & Yes (\%) & No (\%) & COR & AOR & P-value \\
\hline \multicolumn{6}{|c|}{ EQA participation } \\
\hline Yes & $8(80 \%)$ & $2(20 \%)$ & $22(3.1-163)$ & $\begin{array}{r}10(0.4- \\
2.231)\end{array}$ & 0.561 \\
\hline No & $3(15 \%)$ & $17(85 \%)$ & 1.00 & 1.00 & \\
\hline \multicolumn{6}{|c|}{ Use of buffered water } \\
\hline Yes & $7(77.8 \%)$ & $2(22.2 \%)$ & $19(27-145)$ & $\begin{array}{l}0.1(0.012- \\
1.07)\end{array}$ & 0.44 \\
\hline No & $4(19 \%)$ & $17(81 \%)$ & 1.00 & 1.00 & \\
\hline \multicolumn{6}{|c|}{ Internal quality control } \\
\hline Yes & $7(63.6 \%)$ & $4(36.4 \%)$ & $6(1.2-34)$ & $\begin{array}{l}1.6 \\
(0.18-141)\end{array}$ & 0.11 \\
\hline No & $4(21.1 \%)$ & $15(78.9 \%)$ & 1.00 & 1.00 & \\
\hline \multicolumn{6}{|c|}{ Practice staining quality } \\
\hline Yes & $5(71.4 \%)$ & $2(28.6 \%)$ & $\begin{array}{c}7(1.07- \\
14.6 .)\end{array}$ & $\begin{array}{l}15(2.35- \\
18.6)\end{array}$ & $0.039^{*}$ \\
\hline No & $6(26.1 \%)$ & $17(73.9 \%)$ & 1.00 & 1.00 & \\
\hline \multicolumn{6}{|c|}{ In service training } \\
\hline Yes & $10(55.6 \%)$ & $8(44.4 \%)$ & $13(1.4-130)$ & $\begin{array}{l}16 \\
(1.3-19.6)\end{array}$ & $0.041^{*}$ \\
\hline No & $1(8.3 \%)$ & $11(91.7 \%)$ & 1.00 & 1.00 & \\
\hline \multicolumn{6}{|c|}{ Qualification } \\
\hline Diploma & $6(30 \%)$ & $14(70 \%)$ & $2(0.48-11)$ & $\begin{array}{l}0.4(0.09- \\
2.05)\end{array}$ & 0.285 \\
\hline B.Sc. & $5(50 \%)$ & $5(50 \%)$ & 1.00 & & \\
\hline \multicolumn{6}{|c|}{ Smearing quality } \\
\hline Yes & $7(70 \%)$ & $3(30 \%)$ & $\begin{array}{l}0.1(0.19- \\
0.61)\end{array}$ & $\begin{array}{l}24 \\
(1.8-31.3)\end{array}$ & $0.037^{*}$ \\
\hline No & $4(20 \%)$ & $16(80 \%)$ & 1.00 & 1.00 & \\
\hline
\end{tabular}

1 -reference group

$C O R$ crude odds ratio, $A O R$ adjusted odds ratio, $\mathrm{Cl}$ confidence interval

* Significant at $\mathrm{P}$-value $<0.05$ 
in malaria microscopy diagnosis [10] while in Ethiopia 7 (6\%) of health facilities participated in malaria microscopy diagnosis [11]. According to malaria laboratory diagnosis EQA scheme guidelines, laboratory professionals must have adequate training on malaria microscopy diagnosis and quality assurance to maintain quality implementation [7]. The study conducted in Hawassa health facility showed $50 \%$ of health facilities had trained laboratory professionals more than not trained [12]. This reflects a scarcity of training and refresher courses in malaria microscopy diagnosis. Low sensitivity and specificity on malaria parasites diagnosis indicated that there were many false negative results; which can lead to delayed treatment, development of serious complications and death.

This study showed that $80 \%$ and above of collected slides were good in staining in 7 (23.3\%) of the health facility laboratories and had better quality in malaria microscopy diagnosis than health facility laboratories with poor blood film staining qualities. The difference was statistically significant [(AOR $=15,95 \%$ CI $(2.35$, 8.61)] which was slightly better than $20 \%$ in the Democratic Republic of the Congo [13], but less than health facilities in Ethiopia at 31 (47\%) [11].

Smearing and staining quality in the study area were known to be poor in routine laboratory settings, which has a great impact on patient results. Poor blood film preparation and staining generates artifacts commonly mistaken for malaria parasites, including bacteria, fungi, stain precipitation, dirty and cell debris. Normal blood components, such as platelets, also confound diagnosis. Improved training and higher quality of smear preparation and staining are required to reduce false readings.

The number of health facility laboratories with good detection and identification of Plasmodium species was $15(50 \%)$ and 20 (66.7\%), respectively. But the overall agreements of health facility laboratory professionals on detection and identification of plasmodium species with reference reader were 78 and $44.6 \%$ which was less than the national guideline recommendation [7]. It was also less than the study conducted in Africa $82 \%$ in parasite identification [14]. However, similar to detection with the study conducted in North Gondar (77\%) [15].

Because of economic constraints, we did not assess all health facilities that perform malaria microscopic examination. Moreover, due to time limitation, the study could not evaluate the performance of health facilities regarding the quality of blood film preparation and staining procedures.

\section{Conclusion}

In all assessed health facilities, malaria laboratory diagnosis was available but the overall quality of malaria microscopy diagnosis was poor. A significant gap was observed which could significantly impact on malaria microscopy quality services including untrained laboratory professionals on malaria microscopy diagnosis and quality assurance, poor blood film preparation, poor staining quality, poor parasite detection and identification.

\section{Abbreviations \\ QBC: quantitative buffy coat; WHO: World Health Organization; EQA: external quality assessment; ISO: International Standard Organization.}

\section{Authors' contributions}

GS was the primary researcher, conceived the study, designed, participated in sample collection, performed laboratory experiments, conducted data analysis and drafted the manuscript for publication. OZ, AS and GT participated in the interpretation of the results and reviewed the initial and final manuscript. All authors read and approved the final manuscript.

\section{Author details \\ ${ }^{1}$ Nekemte Regional Laboratory, Nekemte, Ethiopia. ${ }^{2}$ Department of Medical Laboratory Sciences, College of Medical and Health Sciences, Wollega Univer-} sity, P.O. Box: 395, Nekemte, Ethiopia.

\section{Acknowledgements}

We would like to thank Nekemte Regional Laboratory and all staff at study site for their cooperation and all study subjects who were volunteered to participate in this study.

\section{Competing interests}

The authors declare that they have no competing interests.

\section{Availability of data and materials}

The data and material set supporting the results of this article is included within the article.

\section{Consent for publication}

Not applicable in this section.

\section{Ethics approval and consent to participate}

Ethical permission was obtained from the Ethical and review committee of Wollega university. Written informed consent was obtained from each participant before collection of samples.

\section{Funding}

Nekemte Regional Laboratory support us financially only for data collection.

\section{Publisher's Note}

Springer Nature remains neutral with regard to jurisdictional claims in published maps and institutional affiliations.

Received: 24 October 2017 Accepted: 12 June 2018

Published online: 18 June 2018

\section{References}

1. WHO. World malaria report. Geneva: World Health Organization; 2017.

2. Cheesbrough M. District laboratory practice in tropical countries. Cambridge: Cambridge University Press; 2006. p. 454. 
3. Raghuveer C, Rajeev A, Bhandari P. Comparative study of peripheral blood smear, quantitative buffy coat and modified centrifuged blood smear in malaria diagnosis. Indian J Pathol Microbiol. 2008;51:108-12.

4. Kettelhut M, Chiodini P, Edwards H, Moody A. External quality assessment schemes raise standards: evidence from the UKNEQAS parasitology sub schemes. J Clin Pathol. 2003;56:927-32.

5. WHO. Malaria microscopy quality assurance manual. Geneva: World Health Organization; 2009

6. Annual East Wollega Zonal Health Department statistical report. June, 2014.

7. Malaria laboratory diagnosis external quality assessment scheme guidelines. Ethiopian Federal Ministry of Health, September 2009.

8. WHO-AFRO Laboratory Accreditation Assessment. Check list For Clinical and Public Health Laboratories- ISO 15189 document requirements for quality, and competence. 2012.

9. Khan MA, Walley JD, Munir MA, Khan MA, Khobar NG, Tahir Z, et al. District level external quality assurance (EQA) of malaria microscopy in Pakistan: pilot implementation and feasibility. Malar J. 2011;10:45.

10. Hailegiorgis B, Girma S, Melaku Z, Teshi T, Demeke L, Gebresellasie S, et al. Laboratory malaria diagnostic capacity in health facilities in five administrative zones of Oromia Regional State, Ethiopia. Trop Med Int Health. 2010;15:1449-57.

11. Abreha T, Alemayehu B, Tadesse Y, Gebresillassie S, Tadesse A, et al. Malaria diagnostic capacity in health facilities in Ethiopia. Malar J. 2014;13:292.

12. Zeleke B, Admasu G, Getachew T, Kebede E, Belay G, Abraha A, et al. External quality assessment of malaria microscopy in Hawassa health facilities, Southern Ethiopia. Clin Med Res. 2015;3:63-8.

13. Mukadi P, Gillet P, Lukuka A, Atua B, Sheshe N, Kanza A, et al. External quality assessment of Giemsa-stained blood film microscopy for the diagnosis of malaria and sleeping sickness in the Democratic Republic of the Congo. Bull World Health Organ. 2013;91:441-8.

14. Frean J, Perovic O, Fensham V, McCarthy K, von Gottberg A, de Gouveia A, et al. External quality assessment of national public health laboratories in Africa, 2002-2009. Bull World Health Organ. 2012;90:191-9.

15. Mitiku K, Mengistu G, Gelew B. The reliability of blood film examination for malaria at the peripheral health unit. Ethiop J Health Dev. 2003;17:197-204
Ready to submit your research? Choose BMC and benefit from:

- fast, convenient online submission

- thorough peer review by experienced researchers in your field

- rapid publication on acceptance

- support for research data, including large and complex data types

- gold Open Access which fosters wider collaboration and increased citations

- maximum visibility for your research: over $100 \mathrm{M}$ website views per year

At BMC, research is always in progress.

Learn more biomedcentral.com/submissions 